\title{
Treatment of Bone Marrow Edema of the Foot and Ankle With the Prostacyclin Analog Iloprost
}

Foot \& Ankle International 2018, Vol. 39(I0) II83-1191 (C) The Author(s) 2018 Article reuse guidelines: sagepub.com/journals-permissions DOI: $10.1177 / 1071100718778557$ journals.sagepub.com/home/fai

\author{
Hubert Hörterer, $M D^{1,2}$ (iD, Sebastian Felix Baumbach, $M D^{3}$ (D), \\ Johanne Gregersen, $M D^{1,2,5}$, Stefanie Kriegelstein, $M D^{1,2}$, \\ Oliver Gottschalk, MD ${ }^{1,2}$, Ulrike Szeimies, MD, \\ and Markus Walther, $M D^{1,2,5}$
}

\begin{abstract}
Background: Bone marrow edema (BME) of the foot and ankle is challenging to treat. One approach is intravenous lloprost treatment, which is a vasoactive prostacyclin analog. The aim of this study was to evaluate the early and intermediate outcome of intravenous lloprost therapy on BME of the foot and ankle and to analyze the influence of its etiology and Association Research Circulation Osseous (ARCO) stage on the outcome.

Methods: This was a retrospective study with prospective follow-up. All patients treated by intravenous lloprost for BME of the foot and ankle (ARCO I-III) at a single orthopedic reference center were included. Demographics, medical history, and MRIs were assessed prior to treatment (t0). MRIs were used to assess the BMEs' etiology (idiopathic/ischemic/metabolic, mechanical/degenerative, traumatic) and severity (ARCO). Complications as well as changes in pain, treatment, and MRI were evaluated after 3 months $(\mathrm{tl})$. The following patient-rated outcome measures (PROMs) were assessed prospectively ( $\mathrm{t} 2)$ : : 12Item Short Form Health Survey (SF-I2), Visual Analog Scale Foot and Ankle (VAS FA), and the Foot Function Index (FFI) (also at $\mathrm{t} 0$ ). The descriptive outcomes and the influence of the etiology and ARCO on the outcome parameters were evaluated. Out of 70 eligible patients, 42 patients (60\%; $47 \pm 15$ years; $30 \%$ female) with a mean follow-up of $28 \pm 19$ months were included. Results: Twelve patients reported minor complications during lloprost therapy. At $\mathrm{tl}$, pain decreased significantly in $56 \%$, and the amount of BME decreased in $83 \%$ of patients. Both parameters correlated moderately $(r=-0.463, P=.015)$. The PROMs at $t 2$ revealed moderate results. The overall FFI improved from $59 \pm 21$ to $30 \pm 22(P<.00 I)$, the overall VAS FA was $68 \pm 20$, the SF-12 Physical Component Summary $42 \pm 12$ and Mental Component Summary $50 \pm 9$. Subgroup analysis revealed no significant influence of the etiology or ARCO stage on any outcome measure.

Conclusion: lloprost therapy for BME of the foot and ankle resulted in a $60 \%$ pain and $80 \%$ edema decrease after 3 months. After 2 years, patient-rated outcome measures showed residual impairment. Neither the etiology nor ARCO stage significantly influenced the outcome.

Level of Evidence: Level III, comparative study.
\end{abstract}

Keywords: llomedin, lloprost, bone marrow edema, foot and ankle

\section{Introduction}

Bone marrow edema (BME) is a pathologic accumulation of fluid within a bone. 5,11 BME most often occurs at the proximal femur, but is also seen in the foot and ankle. ${ }^{3-5,14,21,24,28,32}$ Its etiology can either be idiopathic, such as in the bone marrow edema syndrome (BMES), or occur secondary to different pathologies. According to the underlying pathology, BMEs should be subgrouped into idiopathic/ischemic/metabolic, mechanical/degenerative, or traumatic. ${ }^{7,12,20}$ Known risk factors for BME include trauma,

\footnotetext{
'Schön Klinik München Harlaching, Center for Foot and Ankle Surgery, Munich, Germany

${ }^{2}$ Paracelsus Medical Private University, Salzburg, Austria

${ }^{3}$ University Hospital Munich, Department of General, Trauma, and

Reconstructive Surgery, Munich, Germany

${ }^{4}$ Radiologie in München Harlaching, Munich, Germany

${ }^{5}$ Department of Orthopedics and Orthopedic Surgery, Julius-

Maximilians-University, Würzburg, Germany
}

Corresponding Author:

Hubert Hörterer, MD, Schön Klinik München Harlaching, Center for

Foot and Ankle Surgery, Munich, Germany.

Email: HHoerterer@Schoen-Kliniken.de 
steroid therapy, hypercortisolism, alcohol abuse, smoking and various coagulopathies. ${ }^{13}$

BME should be radiographically classified according to ARCO (Association Research Circulation Osseous). ${ }^{25}$ The ARCO classification was developed to stage avascular femoral head necrosis and is based on radiographs, computed tomography (CT), and magnetic resonance imaging (MRI). ${ }^{22}$ It allows grading from a reversible bone marrow edema (ARCO I) to an irreversible local necrosis (ARCO II) with subchondral fractures (ARCO III) and secondary osteoarthritis (ARCO IV). ${ }^{26}$

BME might progress into avascular necrosis (AVN). Therefore, early diagnosis, identification of the underlying pathology, and treatment initiation are essential. BME with reversible causes usually presents with weight-dependent pain and resolves over 6 to 18 months. ${ }^{20}$ Therefore, an initial conservative treatment approach should be emphasized. This includes non-weightbearing or partial-weightbearing, nonsteroidal anti-inflammatory drugs, as well as physio-, relaxation-, and massage therapy. ${ }^{21}$

In case of failed improvement, additional pharmacologic therapy can be considered. Bisphosphonates and Iloprost are 2 drugs frequently administered off-label to treat bone marrow edema (ARCO I-II). ${ }^{13,28}$ Whereas bisphosphonates inhibit bone resorption, Iloprost is a vasoactive prostacyclin analog $\left(\mathrm{PGI}_{2}\right)$. In a retrospective study, Baier et al found a greater pain reduction for Iloprost within the first 3 months compared to bisphosphonates. No significant differences between the 2 groups were observed after 6 months. ${ }^{5}$ There are conflicting data on the effect of those drugs in ARCO stages II and III. ${ }^{10,13,19}$ Because of the proposed quicker pain relief, intravenous Iloprost has become the preferred drug treatment approach in case of failed conservative treatment in patients with BME at the authors' reference center.

The effectiveness of either drug has not sufficiently been studied for BME of the foot and ankle. ${ }^{21,28}$ Aigner et al found promising results in 19 patients with BME of the hindfoot. ${ }^{2}$ Röhner et al on the contrary found no significant pain relief over 3 months following Iloprost therapy in 23 patients with BME of the foot and ankle for ARCO stage I-II. ${ }^{24}$ No study has yet investigated a possible influence of the etiology on BME drug treatment results.

In the authors' orthopedic foot and ankle reference center, intravenous Iloprost therapy is conducted over a period of 5 days in case of BME of the foot and ankle (ARCO stage I-III) and failed conservative treatment. To our knowledge, no study has assessed the value of intravenous Iloprost therapy in case of BME of the foot and ankle in ARCO stage I-III and analyzed outcome difference between the different etiologic subgroups.

The aim of this study was to evaluate the early and intermediate results of intravenous Iloprost therapy on bone marrow edema of the foot and ankle. Of special interest were the subgroup analysis on the etiologies and ARCO stages (I through III).

\section{Methods}

The study design was retrospective with a prospective follow-up at a single orthopedic reference center. The study was approved by the local ethics committee .

\section{Patient Selection}

The department's clinical database was searched for the basic documentation (Bado) "Ilomedin" and the ICD-10 code M87.XX between January 1, 2009, and June 30, 2015. The inclusion criteria were age $\geqslant 18$ years, in-house intravenous Iloprost therapy without accompanying surgical intervention, initial MRI imaging available for review, and a prospective follow-up of at least 6 months. Excluded were patients with concomitant injuries, BME ARCO IV, contraindication for an Iloprost therapy, or patients unable to provide informed consent. Figure 1 illustrates the patient selection process. Of the 116 patients identified, 70 met the inclusion criteria. A prospective follow-up was available for 42 patients $(60 \%)$.

Forty-two patients with a mean age of $47 \pm 15$ years (1974 years), $30 \%$ female, were included in the final analysis. The left side was affected in $43 \%$, and the mean body mass index (BMI) was $26 \pm 5$ (range 18-28). Duration of symptoms was $11 \pm 9$ months (range 4-25 months). The descriptives on the cause, localization, and initial MRI findings are presented per etiology in Table 1.

\section{Treatment Regimen}

The initial diagnostics were conducted in our out-patient clinic. Patients with symptomatic BME for at least 3 months with failed conservative treatment were offered the in-house Iloprost therapy. Conservative treatment must have been composed of partial weightbearing, nonsteroidal antiinflammatory drugs, and complex physiotherapy. ${ }^{21}$ Informed consent including the off-label use was obtained from every patient.

A cumulative dose of $180 \mu \mathrm{g}$ Ilomedin (IloprostTrometamol $20 \mu \mathrm{g} / 1 \mathrm{~mL}$; Bayer Vital GmbH, Leverkusen, Germany) was given over 5 days. On day one, $20 \mu \mathrm{g}$ of Ilomedin was administered over 6-8 hours. If tolerated well, the dose was increased to $40 \mu \mathrm{g}$ per day. All patients received physiotherapy and analgesics on demand. Weightbearing as tolerated was allowed. Patients were advised to avoid contact sports for 3 months. A follow-up visit in our outpatient clinic was scheduled 3 months following the intervention. Eligible patients were invited for a final follow-up by mail or phone. 


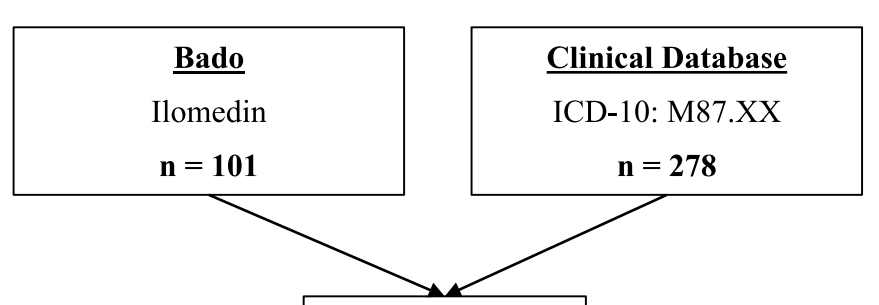

Total patients recieving Ilomedin

$$
\mathrm{n}=116
$$

Excluded

-Additional procedures: $\mathrm{n}=6$

-Foreign patients / no access: $\mathrm{n}=2$

- Chronic polyarthritis: $\mathrm{n}=4$

-Additional injuries: $\mathrm{n}=8$

-Previous Ilomedin/Bisphosphonates: $\mathrm{n}=16$

-No informed consent: $\mathrm{n}=10$

Eligible patients

$\mathrm{n}=70$

Lost to follow-up: $\mathrm{n}=11$

Refusal: 17

Included in final

analysis

$\mathrm{n}=42$

Figure I. Flow-chart illustrating patient selection. Bado, basic documentation; n, number of patients.

Table I. Descriptives on Etiology, Localization, and Initial MRI Findings.

\begin{tabular}{|c|c|c|c|c|}
\hline Etiology & Cause & Location & ARCO & Extension \\
\hline $\begin{array}{l}\text { Idiopathic / ischemic / } \\
\text { metabolic: } \\
n=11(26 \%)\end{array}$ & $\begin{array}{l}\text { Idiopathic: } n=6 \text { Avascular } \\
\text { osteonecrosis: } n=5(12 \%)\end{array}$ & $\begin{array}{l}\text { Talus: } \mathrm{n}=5(12 \%) \\
\text { Metatarsal: } \mathrm{n}=2(5 \%) \\
\text { Navicular: } \mathrm{n}=1(2 \%) \\
\text { Sesamoid: } \mathrm{n}=2(5 \%) \\
\text { Cuneiform } \mathrm{n}=1(2 \%)\end{array}$ & $2.3 \pm 0.8$ & $\begin{array}{l}\text { Minimal: } n=0 \\
\text { Moderate: } n=2(5 \%) \\
\text { Extended: } n=9(21 \%)\end{array}$ \\
\hline $\begin{array}{l}\text { Mechanical / } \\
\text { Degenerative } \\
n=16(38 \%)\end{array}$ & $\begin{array}{l}\text { Osteoarthritis: } n=6(14 \%) \\
\text { Postoperative: } n=3(7 \%) \\
\text { Osteochondral lesion: } n= \\
7(17 \%)\end{array}$ & $\begin{array}{l}\text { Talus: } \mathrm{n}=9(2 \mathrm{I} \%) \\
\text { Metatarsal: } \mathrm{n}=\mathrm{I}(2 \%) \\
\text { TN-joint: } \mathrm{n}=\mathrm{I}(2 \%) \\
\text { TMT II joint: } \mathrm{n}=\mathrm{I}(2 \%) \\
\text { Cuboid: } \mathrm{n}=\mathrm{I}(2 \%) \\
\text { Tarsal bones: } \mathrm{n}=2(5 \%) \\
\text { Tibia: } \mathrm{n}=\mathrm{I}(2 \%)\end{array}$ & $2.1 \pm 0.7$ & $\begin{array}{l}\text { Minimal: } n=1(2 \%) \\
\text { Moderate: } n=7(17 \%) \\
\text { Extended: } n=8(19 \%)\end{array}$ \\
\hline $\begin{array}{l}\text { Traumatic } \\
n=15(36 \%)\end{array}$ & $\begin{array}{l}\text { Posttraumatic: } n=12(29 \%) \\
\text { Stress fracture: } n=3(7 \%)\end{array}$ & $\begin{array}{l}\text { Talus: } n=4(10 \%) \\
\text { Metatarsal: } n=3(7 \%) \\
\text { Sesamoid: } n=3(7 \%) \\
\text { Cuneiform: } n=1(2 \%) \\
\text { Cuboid: } n=1(2 \%) \\
\text { Hindfoot: } n=3(7 \%)\end{array}$ & $1.3 \pm 0.6$ & $\begin{array}{l}\text { Minimal: } n=0 \\
\text { Moderate: } n=9(21 \%) \\
\text { Extended: } n=6(14 \%)\end{array}$ \\
\hline
\end{tabular}

Abbreviation: ARCO, Association Research Circulation Osseous. 
Table 2. Etiology of Bone Marrow Edema. ${ }^{a}$

\begin{tabular}{|c|c|}
\hline Category & Etiology \\
\hline $\begin{array}{l}\text { Idiopathic / ischemic / } \\
\text { metabolic }\end{array}$ & $\begin{array}{l}\text { Avascular osteonecrosis } \\
\text { Complex regional pain syndrome } \\
\text { Transient osteoporosis } \\
\text { Bone marrow edema syndrome }\end{array}$ \\
\hline $\begin{array}{l}\text { Mechanical / } \\
\text { degenerative }\end{array}$ & $\begin{array}{l}\text { Osteoarthritis } \\
\text { Tumor } \\
\text { Postoperative } \\
\text { Osteochondrosis dissecans }\end{array}$ \\
\hline Traumatic & $\begin{array}{l}\text { Posttraumatic bone marrow } \\
\text { edema } \\
\text { Microfracture } \\
\text { Stress fracture }\end{array}$ \\
\hline
\end{tabular}

${ }^{a}$ Adapted from Hofmann et al. ${ }^{12}$

\section{Data Assessment}

Retrospective data were gathered from the clinical database. Assessment included general demographics, BMI, and medical history. BME was rated on initial MRI images and classified for its etiology (Table 2), ARCO stage, location, and extent (3 items: minimal, moderate, extended). Three-month follow-up MRIs were used to measure the BME change over time (5 items: severely increased [+2] to severely improved $[-2]) .^{12,20,26}$ An example is illustrated in Figure 2. MRI classification was conducted by a musculoskeletal-trained senior consultant radiologist and 2 fellowship-trained foot and ankle surgeons (U.S., H.H., S.F.B.).

Throughout the in-house stay, any complication was recorded. According to the available out-patient follow-up documentation, the change in pain 3 months after the treatment was assessed (7 item scale: severely worsened [ $[-3]$ to eliminated [+3]) and any change in the treatment regimen was recorded. ${ }^{20}$ Patient-rated outcome measures (PROMs) were assessed in a prospective follow-up, which patients were invited to. The scores used were a quality of life score (SF-12) and 2 foot and ankle-specific outcome scores, that is, the Visual Analog Scale Foot and Ankle (VAS FA), and the Foot Function Index (FFI). ${ }^{9,15,23}$ The latter is routinely assessed in the authors' department. Therefore, it was also available prior to the treatment ( $\mathrm{t} 0)$.

\section{Outcome Parameters}

The above-outlined outcome parameters were subgrouped to 3 time points, $t 0$ initial outpatient clinic visit, t1 3-month follow-up, and $t 2$ final follow-up. These are recapped in Figure 3. The primary outcome parameter was the PROM FFI assessed at t0 and t2. Secondary outcome parameters were the MRI findings and pain at $\mathrm{t} 1$, as well as the PROM SF-12 and VAS FA at t2. In order to identify factors affecting the outcome, subgroup analysis was conducted for etiology and ARCO stages on the outcome parameters.

\section{Statistics}

A Shapiro Wilk test revealed normal distribution. Next to general descriptive statistics, independent and paired Student $t$ test, analysis of variance (post hoc Bonferroni), chi-square test, and Pearson correlations were conducted. If not stated otherwise, results are given as means \pm standard deviation (range). Because of the retrospective study design, a sample size estimation could not be calculated. Because of multiple testing, an alpha-level correction (Bonferroni) was conducted $(P<.01)$ for the secondary outcome parameters. Statistics were computed using SPSS v. 21 (IBM Corp, Armonk, NY).

\section{Results}

\section{In-house}

On average, patients were in-house for $5 \pm 0.2$ days (5-6 days). Minor complications associated with the intravenous Iloprost therapy were observed in 12 patients $(29 \%)$, with at least 1 of the following symptoms: headache (12 times), nausea ( 2 times), and hypertension ( 2 times).

\section{Three-Month Follow-up (tI): Pain and MRI}

At t1 follow-up (3 months, $\mathrm{n}=34(81 \%)$ ), 56\% reported considerable pain decrease $(+3 /+2)$ and $38 \%$ experienced no or minimal pain relief $(+1 / 0)$. In $6 \%$, the pain increased slightly $(-1)$. Four patients $(10 \%)$ necessitated further treatment. Two patients underwent microfracturing, 1 patient had operative debridement of the subtalar joint, and 1 patient had local injection therapy. A follow-up MRI was available for $29(69 \%)$ patients. The BME decreased considerably $(-2 /-1)$ in $83 \%$. No change (0) was observed in $14 \%$ of the patients. Only in 1 patient $(3 \%)$ was a slight increase of the BME detected. There was a moderate correlation between pain and $\mathrm{BME}$ reduction $(\mathrm{r}=-0.463, P=.015)$.

\section{Final Follow-up (t2): PROMs}

The mean prospective follow-up (t2) was $28 \pm 19$ months (7-73 months) after treatment. The FFI initially (t0) was overall $59 \pm 21$ (7-93), for the subscale pain $52 \pm 19$ (7-89) and for the subscale function $65 \pm 24$ (7-97). At final follow-up (t2) the FFI decreased overall to $30 \pm 22(0-73)$ and to $21 \pm 16(0-57) / 33 \pm 25(0-74)$ for the subscales pain and function. In 27 patients (64\%), both at t0 and t2, FFI scores were available. The paired Student $t$ test showed a significant decrease for all FFI scales $(P<.001)$, which remained true for the independent sample $t$-test on the whole population $(P<.001)$. The overall VAS FA score at final follow-up was $68 \pm 20$ (21-100). Scores for the subscales pain, function, and others were $65 \pm 21$ (17-100), $68 \pm 22$ (16-100), and $71 \pm 19$ (29-98), respectively. The SF-12 Physical 


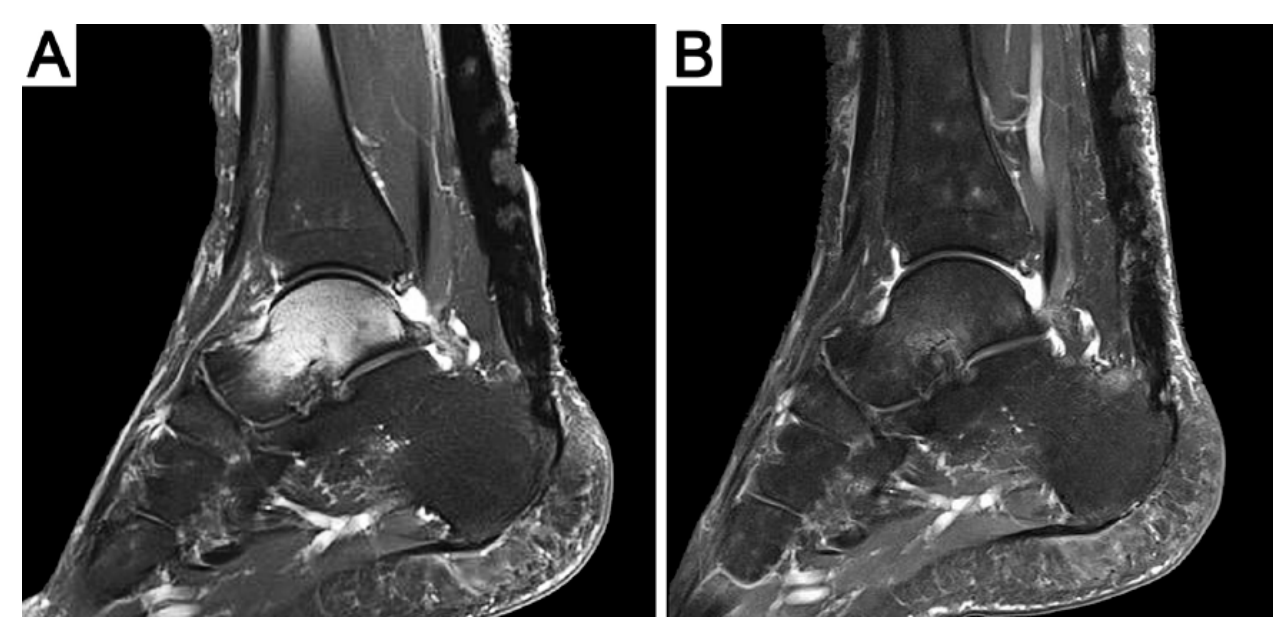

Figure 2. Illustration of a pre- $(A)$ and postintervention MRI (B) of an idiopathic BME of the talus. Images of a 57-year-old male patient suffering an idiopathic BME. At 3 months, follow-up ( $t$ I) pain had improved considerably (+2) and the BME (ARCO 2) had decreased (-I). At final follow-up, the PROMs were as follows: FFI, 2I; VAS FA, 69; SF-12 PCS, 45; SF-12 MCS, 57. (BME, bone marrow edema; MCS, Mental Component Summary; MRI, magnetic resonance imaging; PCS, Physical Component Summary; PROMs, patient-rated outcome measures; SF-12, 12-Item Short Form Health Survey.)

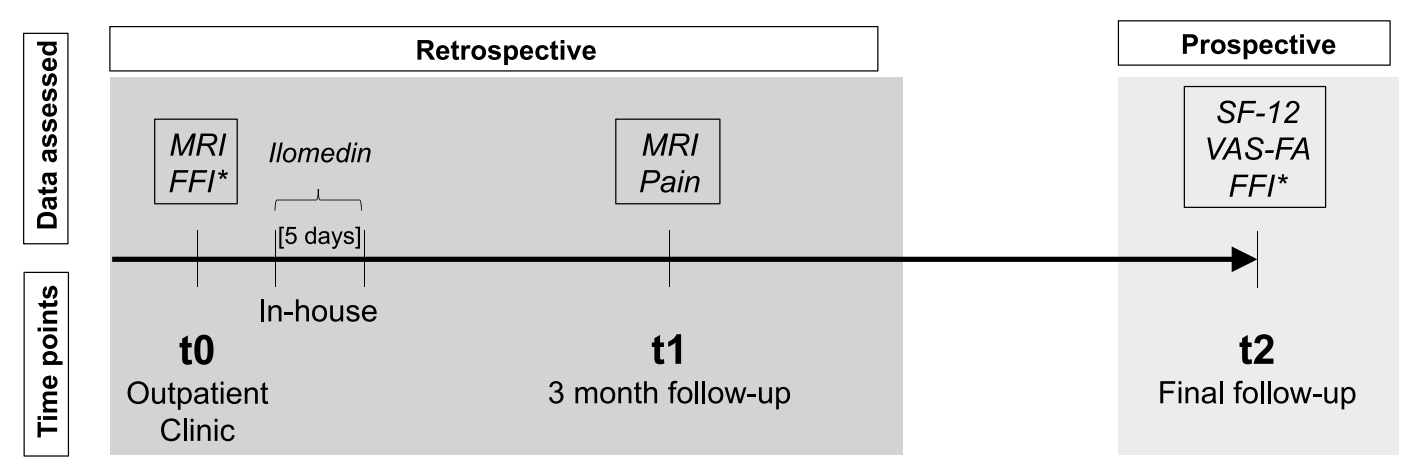

Figure 3. Timeline of data assessment.

*Primary outcome parameter.

Component Summary (PCS) was $42 \pm 12$ (23-59) and the Mental Component Summary (MCS) $50 \pm 9$ (30-64).

\section{Subgroup Analysis}

To identify factors affecting the outcome, a subgroup analysis was conducted. Etiology had no significant impact on any FFI parameter, neither at $\mathrm{t} 0$ nor at $\mathrm{t} 2$ (Figure 4). Table 3 depicts a possible effect of the etiology on any secondary outcome parameter. Only the ARCO classification showed significant differences $(P=.001)$. Traumatic BME had significantly lower ARCO scores compared to idiopathic/ischemic/metabolic $(P=.002)$ or mechanical/degenerative $(P=$ .006) causes. Further subgroup analysis revealed that the ARCO classification had no significant influence $(P=.109$ $.774)$ on any primary or secondary outcome parameter. No significant correlation (Pearson) could be found between age $(P=.169-.856)$, BMI $(P=.346-.982)$, or duration of symptoms $(P=.245-.997)$ and any outcome parameter. In a final step, the population was divided into 2 groups per the reported pain decrease at 1 . Group $1(56 \%)$ were those patients with a considerable pain decrease $(+3 /+2)$. Group 2 were patients with a pain score $<+2$. Table 4 depicts those 2 groups per the etiology of the BME. Overall, the chisquared test revealed no significant differences $(P=.063)$.

\section{Discussion}

The current study reported on the outcome of intravenous Iloprost therapy in 42 patients with BME of the foot and ankle of different etiologies and ARCO stages. Twelve patients (29\%) had minor complications. At the 3-month (t1) 


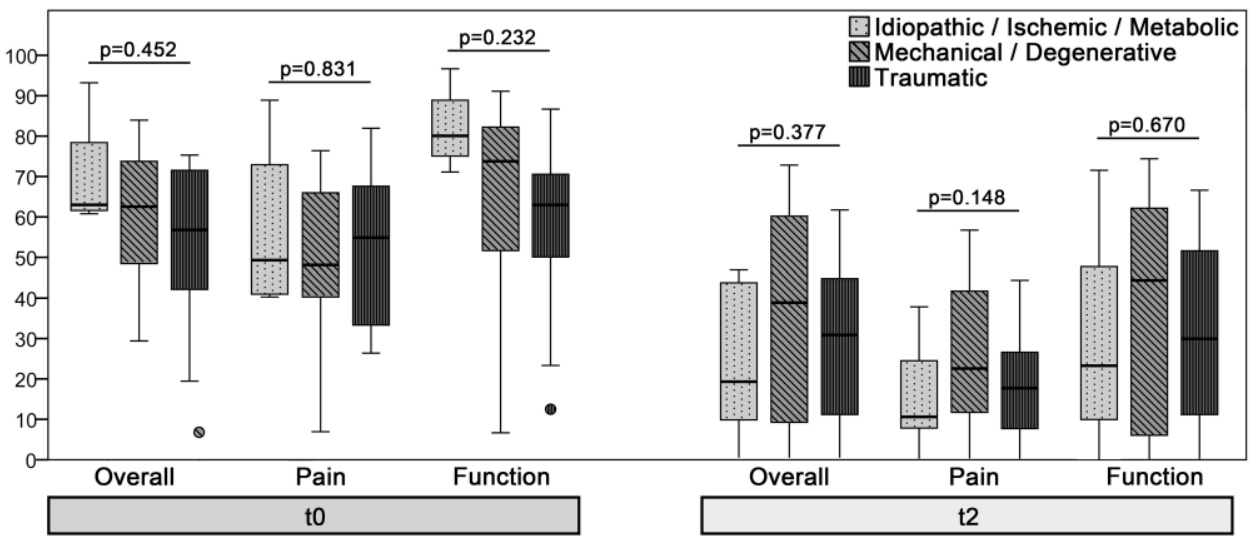

Figure 4. FFI subgroup analysis per etiology. FFI, Foot Function Index; t0, outpatient clinic; t2, final follow-up.

Table 3. Secondary Outcome Parameter per Etiology.

\begin{tabular}{|c|c|c|c|c|c|c|c|c|c|c|}
\hline \multirow{2}{*}{$\begin{array}{l}\text { Etiology } \\
\text { Idiopathic / } \\
\text { ischemic / } \\
\text { metabolic; } n=1 \text { I } \\
(26 \%)\end{array}$} & \multicolumn{2}{|c|}{ ARCO Stage } & \multicolumn{2}{|c|}{$\begin{array}{l}\text { Pain at } \mathrm{tl} \\
\quad(3 \mathrm{mo})\end{array}$} & \multicolumn{2}{|c|}{$\begin{array}{c}\text { MRI at tl } \\
(3 \mathrm{mo})\end{array}$} & \multicolumn{2}{|c|}{ VAS FA at $\mathrm{t} 2$} & \multicolumn{2}{|c|}{$S F-12$ at $t 2$} \\
\hline & $2.3 \pm 0.8$ & $P=.001$ & $1.6 \pm 1.0$ & $P=.135$ & $-1.0 \pm 0.8$ & $P=.379$ & $\begin{array}{l}\text { Overall: } 75 \pm 17 \\
\text { Pain: } 72 \pm 18 \\
\text { Function: } 75 \pm 19 \\
\text { Other: } 75 \pm 16\end{array}$ & $\begin{array}{l}\text { Overall: } \\
P=.366 \\
\text { Pain: } \\
P=.491\end{array}$ & $\begin{array}{l}\text { PCS } \\
44 \pm 11 \\
\text { MCS } \\
52 \pm 11\end{array}$ & $\begin{array}{l}\text { PCS } \\
P=.504 \\
\text { MCS } \\
P=.561\end{array}$ \\
\hline $\begin{array}{l}\text { Mechanical / } \\
\text { degenerative: } \\
16(38 \%)\end{array}$ & $2.1 \pm 0.7$ & & $0.8 \pm 1.0$ & & $-1.1 \pm 0.7$ & & $\begin{array}{l}\text { Overall: } 63 \pm 22 \\
\text { Pain: } 61 \pm 22 \\
\text { Function: } 62 \pm 25 \\
\text { Other: } 68 \pm 21\end{array}$ & $\begin{array}{l}\text { Function: } \\
P=.281 \\
\text { Other: } \\
P=.660\end{array}$ & $\begin{array}{l}\text { PCS } \\
39 \pm 12 \\
M C S \\
48 \pm 8\end{array}$ & \\
\hline $\begin{array}{l}\text { Traumatic: } n=15 \\
\quad(36 \%)\end{array}$ & $1.3 \pm 0.6$ & & $1.6 \pm 1.2$ & & $-1.5 \pm 1.0$ & & $\begin{array}{l}\text { Overall: } 69 \pm 20 \\
\text { Pain: } 64 \pm 23 \\
\text { Function: } 70 \pm 21 \\
\text { Other: } 72 \pm 19\end{array}$ & & $\begin{array}{l}\text { PCS } \\
44 \pm 12 \\
\text { MCS } \\
49 \pm 9\end{array}$ & \\
\hline
\end{tabular}

Abbreviations: ARCO, Association Research Circulation Osseous; MCS, Mental Component Summary; MRI, magnetic resonance imaging; PCS, Physical Component Summary; VAS FA, Visual Analog Scale Foot and Ankle.

Table 4. Influence of Etiology on Pain at $\mathrm{tl}$.

\begin{tabular}{lccc}
\hline & Idiopathic / Ischemic / Metabolic, \% & Mechanical / Degenerative, \% & Traumatic \\
\hline $\begin{array}{l}\text { Group I }(n=15) \\
\text { Pain at } t I+3 /+2\end{array}$ & 20 & 60 & 20 \\
Group $2(n=19)$ & 32 & 21 & 47 \\
Pain at $\mathrm{t} l<+2$ & & & \\
\hline
\end{tabular}

follow-up, a considerable pain decrease was observed in $56 \%$ and a BME reduction in $83 \%$ of patients $(\mathrm{r}=-0.463, P$ $=.015)$. At final follow-up $(28 \pm 19$ months $)$, the PROM FFI had decreased significantly. Still, all assessed PROMs (FFI, SF-12, VAS FA) showed residual impairment. Subgroup analysis revealed no significant influence of the etiology, age, BMI, or ARCO stage on any outcome parameter.
The demographics compare well to previous studies. ${ }^{2,5,13,20,24}$ Despite no significant alterations for the duration of in-house stay ( $5 \pm 0.2$ days (5-6 days)), a medication associated complication rate of $29 \%$ was observed. The observed minor complications are in line with previous studies. But their rate compares favorably to an average published complication rate of $50 \%$. $^{2,3,5,8,20}$ 
The primary pain-relieving effect of Iloprost on BME has been described to occur within the first 3 months. ${ }^{5,13} \mathrm{We}$ observed considerable pain decrease in almost $60 \%$ of patients after 3 months, which is in the range of previous studies. In one of the largest prospective studies $(n=95)$ on BME of various locations, Jäger et al reported a decrease by 2.8 to 2.2 points (1-9) on the visual analog scale (VAS). ${ }^{13}$ Baier et al retrospectively reported a VAS decrease by 5 to 1 points in 20 patients treated for BME of the knee or foot and ankle. ${ }^{5}$ Meizer et al retrospectively assessed the outcome at 4 months in 104 patients with BME of various locations. ${ }^{20}$ Using a 6-item Likert-type scale, pain decreased by 2 to 1 point. At rest, $64 \%$ reported a reduction in pain, $34 \%$ no change, and $2 \%$ an increase in pain. All these figures are in line with our reported values.

The current study showed a considerable BME decrease in more than $80 \%$ of patients on MRI. This is in line with reported high, but varying, remission rates 3 months after intravenous Iloprost. ${ }^{3,4}$ Meizer et al retrospectively found a BME decrease of the knee, talus and navicular bone in $65 \%$ of patients. ${ }^{20}$ In a RCT ( $\left.n=21\right)$ Mayerhoefer et al showed a BME decrease in 58\%. ${ }^{17} \mathrm{~A}$ complete remission was published retrospectively by Röhner et al including only patients with ARCO stage I-II. ${ }^{24}$ Studies on BME with ARCO stages III-IV found no change in BME after intravenous Iloprost therapy. ${ }^{8,13}$ Still, none of these studies investigated the influence of the ARCO stage on the BME decrease.

The current study showed a moderate correlation between pain and BME reduction $(\mathrm{r}=-0.463, P=.015)$. Comparably moderate correlations were reported in previous studies. ${ }^{30,31}$ For BME size and knee pain, Unay et al found a weak but significant correlation for the Stanmore Functional Rating Scale (SFRS) $(\mathrm{r}=0.313, P=.025)$ but no correlation for the VAS $(\mathrm{r}=0.203, P=.153){ }^{31}$ Tonbul et al reported on idiopathic BME of the talus, showing a poor correlation to the AOFAS scores $(\mathrm{r}=0.313, P=.025)$ and no correlation to the VAS $(\mathrm{r}=0.203, P=.153) .{ }^{30}$ These consistent findings raise the question on where the residual pain originates from. To address this question, the current study grouped BMEs per etiology and conducted a subgroup analysis. None of the chosen categories had a significant influence on any outcome parameter. Therefore, the reason for the discrepancy between BME and pain decrease remains unclear.

The primary outcome parameter overall FFI decreased significantly on average by $49 \%$ to $30 \pm 22$ points $(0-73, P<$ $.001)$ at final follow-up. This significant decrease was similar in all subscales. Schneider et al assessed age- and sexrelated normative data for the FFI with a mean FFI overall scores of healthy individuals (40-49 years) of 17 points. ${ }^{27}$ The herein observed overall VAS FA value of $68 \pm 20$ points was also below the corresponding reference values for healthy individuals (86-100) but comparable to patients with an isolated hallux valgus (45-83). ${ }^{29}$ Consequently, the herein observed values for the foot and ankle-specific PROMS, that is, FFI and VAS FA, resemble a light to moderate impairment $28 \pm 19$ months after intravenous Iloprost therapy for BME of the foot and ankle.

Only 3 studies have assessed the outcome of Iloprost therapy on BME of the foot and ankle using outcome measures. ${ }^{2,3,24}$ Aigner et al published 2 studies with 5 $\mathrm{BME}$ of the talus and $19 \mathrm{BME}$ of the hindfoot, respectively. ${ }^{2,3}$ They showed a significant increase of the Mazur Foot Score from 58 to 93 points and from 55 to 88 points after 3 months. Röhner et al (BME of the foot and ankle, $\mathrm{n}=23$ ) found no significant VAS decrease but a significant increase for the Ankle Hindfoot Scale (55-70) and the Kaikkonen Scale (49-69) after 3 months. ${ }^{24}$ Consequently, intravenous Iloprost therapy partially decreased pain but led to residual impairment. ${ }^{2,24}$

Keeping in mind the overall moderate PROM scores at final follow-up, efforts were made to identify possible factors that could help to identify patients predominantly benefiting from intravenous Iloprost therapy. Neither the etiology of the BME, nor the ARCO stage, correlated to any of the evaluated PROMs. Still, idiopathic/ischemic/metabolic BME resulted in nonsignificant better mean PROM values than mechanical/degenerative or traumatic BME. With regard to the limited power of the study, future studies with greater group sizes might be able to define these differences. Two studies reported similar descriptive results. ${ }^{2,20}$ Aigner et al showed better results on the Mazur's score for ischemic (56.2-93.9) compared to osteoarthritic and stress BME (53-79.3). ${ }^{2}$ Meizer et al found a greater pain decrease for idiopathic BME ( $87 \%$ at rest, $75.2 \%$ at stress) compared to degenerative BME ( $64 \%$ and $48 \%$ ). Still both studies did not assess those changes statistically. ${ }^{20}$ This is the first study to statistically analyze the influence of the ARCO stages on PROM.

\section{Strengths and Limitations}

Several limitations need to be discussed. First, no sample size calculation was conducted. Second, the retrospective design limits the statistical analysis but also explains the follow-up rate of $60 \%$. Still most studies on this topic are retrospective..$^{3,5,8,16,20,24}$ and the follow-up rate achieved is comparable to studies with a similar design. ${ }^{6,18,33}$ A further limitation could be the number of patients included. Other than few larger studies, most papers report on fewer patients. ${ }^{1,3,5,8,16,17,20,24}$ Nevertheless, this is by far the largest cohort study on BME of the foot and ankle. ${ }^{2,3,24} \mathrm{~A}$ final limitation is the lack of a control group. A control group, either treated by bisphosphonates or physiotherapy alone, would have allowed to assess differences at 3 months and final follow-up. Future prospective randomized trials should include a control group to assess the actual value 
of drug therapy. These data will furthermore help to assess treatment costs (drug and hospital stay) to the actual treatment benefit.

Despite the above-outlined limitations, several strengths of this study are noteworthy. First, the prospective, intermediate follow-up of more than 2 years is important. Second, the radiographic evaluation was conducted by a musculoskeletal radiologist and 2 fellowship-trained foot and ankle specialists. Finally, in addition to the radiographic changes, general as well as foot- and ankle-specific PROMs were chosen to evaluate the prospective follow-up.

\section{Conclusion}

Overall, Iloprost therapy resulted in almost $60 \%$ pain decrease and in more than $80 \%$ of patients in a pronounced reduction of the BME within the first 3 months of treatment. After more than 2 years, the general as well as foot and ankle-specific PROMs showed residual impairment. Neither the etiology nor the ARCO stage of the BME had a significant influence on any outcome parameter. Consequently, treating patients with BME with intravenous Iloprost did not completely resolve their pain, independent of the BME's etiology or ARCO stage.

\section{Declaration of Conflicting Interests}

The author(s) declared no potential conflicts of interest with respect to the research, authorship, and/or publication of this article. ICMJE forms for all authors are available online.

\section{Funding}

The author(s) received no financial support for the research, authorship, and/or publication of this article.

\section{ORCID iDs}

Hubert Hörterer, MD, iD https://orcid.org/0000-0001-6151-5778 Sebastian Felix Baumbach, MD, iD https://orcid.org/0000-00026287-6206

\section{References}

1. Aigner N, Meizer R, Meraner D, Becker S, Meizer E, Landsiedl F. Bone marrow edema syndrome in postpartal women: treatment with Iloprost. Orthop Clin North Am. 2009;40(2):241-247.

2. Aigner N, Meizer R, Stolz G, et al. Iloprost for the treatment of bone marrow edema in the hindfoot. Foot Ankle Clin. 2003;8(4):683-693.

3. Aigner N, Petje G, Steinboeck G, Schneider W, Krasny C, Landsiedl F. Treatment of bone-marrow oedema of the talus with the prostacyclin analogue Iloprost. An MRI-controlled investigation of a new method. J Bone Joint Surg Br. 2001;83(6):855-858.

4. Arazi M, Yel M, Uguz B, Emlik D. Be aware of bone marrow edema syndrome in ankle arthroscopy: a case successfully treated with Iloprost. Arthroscopy. 2006;22(8):909.e1-909.e3.

5. Baier C, Schaumburger J, Götz J, et al. Bisphosphonates or prostacyclin in the treatment of bone-marrow oedema syn- drome of the knee and foot. Rheumatol Int. 2012;33(6):13971402.

6. Baumbach SF, Prall WC, Kramer M, Braunstein M, Böcker W, Polzer H. Functional treatment for fractures to the base of the 5th metatarsal - influence of fracture location and fracture characteristics. BMC Musculoskelet Disord. 2017;18(1):534.

7. Beckmann J, Roth A, Niethard C, Mauch F, Best R, Maus U. Bone marrow edema and atraumatic necrosis of the femoral head: therapy [in German]. Orthopäde. 2015;44(9):662-671.

8. Beckmann J, Schmidt T, Schaumburger J, et al. Infusion, core decompression, or infusion following core decompression in the treatment of bone edema syndrome and early avascular osteonecrosis of the femoral head. Rheumatol Int. 2013;33(6):1561-1565.

9. Budiman-Mak E, Conrad KJ, Roach KE. The Foot Function Index: a measure of foot pain and disability. J Clin Epidemiol. 1991;44(6):561-570.

10. Claßen T, Becker A, Landgraeber S, et al. Long-term clinical results after Iloprost treatment for bone marrow edema and avascular necrosis. Orthop Rev (Pavia). 2016;8(1):6150.

11. Craiovan BS, Baier C, Grifka J, Götz J, Schaumburger J, Beckmann J. Bone marrow edema syndrome (BMES). Orthopäde. 2013;42(3):191-204.

12. Hofmann S, Kramer J, Breitenseher M, Aigner N. Das schmerzhafte Knochenmarködem im Kniegelenk [Painful bone marrow edema in the knee joint]. Arthroskopie. 2003; 16(2):88-101.

13. Jäger $M$, Zilkens $C$, Bittersohl B, et al. Efficiency of Iloprost treatment for osseous malperfusion. Int Orthop. 2010;35(5):761-765

14. Martin RL, Irrgang JJ. A survey of self-reported outcome instruments for the foot and ankle. J Orthop Sports Phys Ther. 2007;37(2):72-84.

15. Maurischat C, Ehlebracht-König I, Kühn A, Bullinger M. Structural validity of the Short Form 36 (SF-36) in patients with rheumatic diseases [in German]. Z Rheumatol. 2005;64(4):255-264.

16. Mayerhoefer ME, Kramer J, Breitenseher MJ, et al. MRIdemonstrated outcome of subchondral stress fractures of the knee after treatment with Iloprost or tramadol: observations in 14 patients. Clin J Sport Med. 2008;18(4):358-362.

17. Mayerhoefer ME, Kramer J, Breitenseher MJ, et al. Shortterm outcome of painful bone marrow oedema of the knee following oral treatment with Iloprost or tramadol: results of an exploratory phase II study of 41 patients. Rheumatology. 2007;46(9):1460-1465.

18. Mehlhorn AT, Zwingmann J, Hirschmüller A, Südkamp NP, Schmal H. Radiographic classification for fractures of the fifth metatarsal base. Skeletal Radiol. 2014;43(4):467-474.

19. Meier C, Kraenzlin C, Friederich NF, et al. Effect of ibandronate on spontaneous osteonecrosis of the knee: a randomized, double-blind, placebo-controlled trial. Osteoporos Int. 2014;25(1):359-366.

20. Meizer R, Radda C, Stolz G, et al. MRT-verifizierte Analyse von 104 mit Iloprost behandelten Patienten mit Knochenmarködemen unterschiedlicher Lokalisation [MRIcontrolled analysis of 104 patients with painful bone marrow edema in different joint localizations treated with the prostacyclin analogue iloprost]. Wien Klin Wochenschr. 2005;117(7-8):278-286. 
21. Mirghasemi SA, Trepman E, Sadeghi MS, Rahimi N, Rashidinia S. Bone marrow edema syndrome in the foot and ankle. Foot Ankle Int. 2016;37(12):1364-1373.

22. Müller HF, Schedel H, Schneller A, et al. Initial nuclear magnetic resonance tomography results of the treatment course of avascular femur head necrosis after femoral core decompression [in German]. Aktuelle Radiol. 1997;7(2):79-85.

23. Richter M, Zech S, Geerling J, Frink M, Knobloch K, Krettek C. A new foot and ankle outcome score: questionnaire based, subjective, visual-analogue-scale, validated and computerized. Foot Ankle Surg. 2006;12(4):191-199.

24. Röhner E, Zippelius T, Steindl D, Fussi J, Perka C. Effects of intravenous Iloprost therapy in patients with bone marrow oedema of the foot and ankle. Eur J Orthop Surg Traumatol. 2014;24(8):1609-1616.

25. Roth A, Beckmann J, Bohndorf K, et al. S3-Guideline nontraumatic adult femoral head necrosis. Arch Orthop Trauma Surg. 2016;136(2):165-174.

26. Schmitt-Sody M, Kirchhoff C, Mayer W, Goebel M, Jansson $\mathrm{V}$. Avascular necrosis of the femoral head: inter- and intraobserver variations of Ficat and ARCO classifications. Int Orthop. 2008;32(3):283-287.
27. Schneider W, Jurenitsch S. Age- and sex-related normative data for the Foot Function Index in a German-speaking cohort. Foot Ankle Int. 2016;37(11):1238-1242.

28. Singh D, Ferrero A, Rose B, Goldberg A, Cullen N. Bone marrow edema syndrome of the foot and ankle: mid- to long-term follow-up in 18 patients. Foot Ankle Spec. 2016;9(3):218-226.

29. Stüber J, Zech S, Bay R, Qazzaz A, Richter M. Normative data of the Visual Analogue Scale Foot and Ankle (VAS FA) for pathological conditions. Foot Ankle Surg. 2011;17(3):166-172.

30. Tonbul M, Guzelant AY, Gonen A, Baca E, Ozbaydar MU. Relationship between the size of bone marrow edema of the talus and ankle pain. J Am Podiatr Med Assoc. 2011;101(5):430-436.

31. Unay K, Poyanli O, Akan K, Guven M, Demircay C. The relationship between bone marrow edema size and knee pain. Knee Surg Sports Traumatol Arthrosc. 2009;17(11):1298-1304.

32. Zanetti M, Steiner CL, Seifert B, Hodler J. Clinical outcome of edema-like bone marrow abnormalities of the foot. Radiology. 2002;222(1):184-188.

33. Zarzaur BL, Kozar RA, Fabian TC, Coimbra R. A survey of American Association for the Surgery of Trauma member practices in the management of blunt splenic injury. $J$ Trauma. 2011;70(5):1026-1031. 